\title{
MARIPOSAS DE PANZA
}

\author{
Ernesto Núñez Montes de Oca*
}

\author{
BELLY BUTTERFLIES **
}

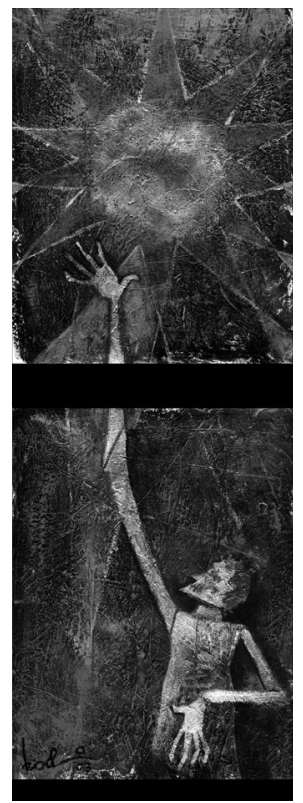

Autor: Rodmi Cordero Cordero
Sentado, con la cabeza apoyada en mi mano, pienso en lo difícil de encontrar unos ojos que inspiren confianza. A mi avanzada edad es común la melancolía y hacer del recuerdo un placer. Medito también sobre la indudable complejidad del sentimiento femenino y en cómo me he llegado a sentir parte de un género sencillo. En momentos así, me gusta recurrir a los textos de la doctora Mareva Ornat que, para dicha de los confundidos y los enamorados, descubrió las grandiosas Mariposas de Panza.

Todavía sale del cenicero el humo blanco del cigarrillo, me inclino hacia atrás y observo atentamente las manchas de mi techo por un instante. De pronto me levanto de mi escritorio, camino hacia el librero que se oculta en la esquina del cuarto y busco el libro. Yo sé que lo tengo; es un libro viejo, que de seguro tendrá algo de polvo. Mi dedo anciano va dibujando una gruesa línea entre los títulos, y allí está, con letras doradas: Mariposas de Panza.

De vuelta en el escritorio busco la cita, los párrafos completos. ¿Dónde era? Mis ojos se mueven como avispas atrapando palabras en la hoja blanca: beso, terrible, ojos, no existe

* $\quad$ Universidad de Costa Rica.

** Traducción: Lic. Geannette Soto. Escuela de Lenguas Modernas, Universidad de Costa Rica. Correo electrónico: erne506mdo@hotmail.com Recepción: 13/02/13. Aceptación: 29/04/13. 
presente hoy; de pronto mis pupilas se agudizan. Vuelvo a ellas después de tantos años.

\section{5 de octubre de 1948}

Las mariposas de panza son seres tan mitológicos como contemporáneos. Cada persona en el centro de su cuerpo posee cierto número de estas bellas criaturas. En cantidades normales, incitan a su dueño a crear y a amar. Más adelante me referiré a la relación de las mariposas con el arte. Desde su maternal recinto, revolotean cuando sienten la presencia de la belleza en el exterior, muéstrese ya sea en una persona, acontecimiento, paisaje o animal. Cada mariposa posee un color definido, y mantienen el color en todo su cuerpo, no solo en las alas. Dentro del grupo pueden haber mariposas de un mismo color. A necesidad de prueba y error, he observado que para su supervivencia requieren de la luz, la que llega por medio de la boca y los ojos del cuerpo que las guarda; para ser más exactos, por las sonrisas y por el brillo de los ojos. Cuanto más luz, más revolotean. Su forma de reproducción está misteriosamente relacionada con los besos que dé y reciba su dueño. Es decir, cuantos más besos, mayor cantidad de mariposas tendrá su panza.

Ahora, al releer a la Dra. Ornat, creo haber encontrado, después de tantos años, un punto en el cual difiero, ¿si entre mayor cantidad de besos, mayor cantidad de mariposas, qué sucede entonces con las personas que de tanto besar se sienten vacías? Después de un cigarro he pensado, tal vez, que la autora no se refiere a cualquier tipo de beso, sino a aquel que guarde un misterio, que sea un beso no para contar sino para recordar. Otra posibilidad he pensado, que la tristeza y la soledad son una forma de alegría que vive en extrañas personas.

\section{Continúo:}

Así como las mariposas son fuente de vida extrema, son igualmente sensibles al dolor. La tristeza las detiene, el miedo las angustia, y el llanto las mata (las lágrimas son la sangre de las muertas). No obstante, se recomienda llorar de risa o ternura de vez en cuando para provocar la muerte de las mariposas cansadas (este tipo de lágrimas, al contacto con la tierra, crean otra especie de mariposas de las cuales hablaré más adelante). En el terrible momento en que solo una mariposa sobrevive en el estómago, esta se elevará hasta su pecho buscando la salida por su boca. Por lo general, cada persona tiene una favorita; es también la más fuerte y, lógicamente, la última. Ya lista en su boca, aprovechará cualquier grito de enojo, el llanto más desesperado o la mentira más grande jamás pronunciada para escapar (el destino de estas mariposas huérfanas es un enigma).

Hablemos ahora brevemente sobre esta última mariposa. Usted sabrá cuando las haya perdido todas porque sentirá un gran vacio en su pecho. Es difícil volver a obtenerlas, y se necesita al menos una dentro de usted para que se reproduzcan; únicamente mediante un beso, llamémoslo mágico, pueden transferirse una o varias mariposas hasta su pecho. Aún alli son muy sensibles y requerirán de un cuidado especial de parte, ahora, de las dos personas.

Tengo que confesar que la reflexión sobre las mariposas me ha tocado, una vez más, el corazón. Después de leer partes del primer informe pienso mucho en mi esposa Valentina, $y$ es que en momentos cuando las relaciones son tan difíciles a veces solo se encuentra razón en los libros o en la música, que a modo de maldición estas pasiones nos devuelven a las mujeres y ellas, a la pasión. Estoy llegando a pensar que me muevo dentro de un mundo donde las mujeres y el arte son lo mismo y no hay escapatoria a esta ruta de locura. Y es que la quiero con toda la piel, con todos los dientes, con cada ojo, con los dos labios, en todo instante; no puede ser menos, a ella le debo mi vida. Hace muchos años pensé en terminar mi existencia, dejar solamente el último cigarro a medias y el silencio, el silencio que queda cuando una vida desaparece. Pero no, no todavía, no mientras exista Valentina, quien poco a poco me devolvió el gusto y el aroma de la felicidad. 
Ya es tarde, y no puedo dormir. Efectivamente, la lluvia se quedó para la noche. Intento escribir algo, eso me desahoga. Observo mi mundo: el cigarro en mi mano, el dolor de cabeza, el sonido de la lluvia que, como olas, pasa corriendo por el techo, el caño que siempre se inunda, la ventana llena de polvo, y esta bendita ausencia que me saca por instantes de este maldito cuarto. Al rato desisto de la escritura y siento la noche, inmensa, incapturable, distante... Como Valentina, que duerme a unos cuantos metros de mí, debajo de las cobijas, a la luz de una pequeña lámpara.

Vuelvo a tomar el libro en mis manos, busco entre las páginas cómo inició todo esto de la tristeza y la alegría. Más tarde, revisando el segundo informe, lo hallo, y es maravilloso, es el origen de las mariposas y de nuestra propia alegría. Cito nuevamente:

\section{7 de diciembre de 1956}

A partir del cuarto mes, en pleno desarrollo del feto, este entra en contacto directo con las mariposas. Dentro de su cómodo recinto maternal, el bebé siente el revolotear de las mariposas y son ellas realmente quienes le dan la bienvenida a la vida y al mundo. Cientos de pequeñas mariposas coloridas se le postran en la cabeza, en el pecho, en los ojos, en los dedos, en toda parte, provocándole asi delicadas cosquillas de manera que, al reír y patear por primera vez, inicia el proceso de creación de sus propias mariposas de panza. La alegría del juego y la protección de la madre, junto con el espectáculo multicolor de mariposas con luz propia (sin alumbrar alrededor), crean inevitablemente la vida. De esta forma, entre el bebé y las mariposas se crea un lazo de amistad, de reconocimiento. Muchas personas, al crecer, tienen un leve recuerdo de ellas, pero se les hace absurda tal teoría. Todos en algún momento las hemos sentido, y son pocos los que vuelven a reír con ellas, a creer en ellas.

Por más que evito a la muerte, esta no deja de hablarme, creo que debo aceptarla y darle espacio en mi vida. Con todo esto de las mariposas luce diferente, como algo tan pequeño, y a la vez tan intrigante, como el horizonte que divide el cielo del mar. Todavía está lloviendo afuera y la verdad es que estoy cansado.

En el prólogo del libro se cuenta la historia de una mujer. Algunas personas afirman que es un texto biográfico de la doctora Mareva Ornat; sin embargo, no hay mucho que confirme tal teoría. Sobre ella existen toda clase de misterios: de su origen, su destino; pero a mí, particularmente, me interesa saber cómo descubrió las Mariposas de Panza, ¿dónde está su fuente de información?, ¿por qué solo ella es experta en mariposas si todos las tenemos? Espero que alguien algún día me pueda aclarar estas dudas. Volviendo al prólogo, es la historia de una mujer, al parecer joven, a la que ese mismo día le queda solamente una mariposa en la panza e intenta salvarse. Recorre la ciudad, cualquiera, sin más fin que comprar flores. En lo personal, me duele pensar que una persona pueda llegar a tan extrema condición de tristeza. Solo una mariposa sobrevive en ella y por lo que he leído es difícil mantenerla adentro; es como intentar retener el llanto cuando ya no queda nada más que llorar. A Valentina se le ocurrió hace muchos años montar un monólogo teatral con esta historia, sin embargo, nunca logró asimilar la idea de la extrema tristeza o de la paupérrima felicidad, como lo quieran entender.

Busco en la habitación la luz de la lámpara, al lado de mi esposa y mientras duerme vuelvo al placer de la relectura. Me voy al inicio del libro y allí, con grandes letras, leo la palabra prólogo. Y cito:

Me ha costado trabajo saber que estoy viva, pero lamentablemente también sé que estoy sola. Por esto he salido a comprar flores. Antes, gasté varios minutos pensando en mi atuendo de hoy. ¿Será día de falda y pañuelos o de jeans y camiseta? Cierta ropa ya no me queda bien, estoy peleada con el espejo. Desde el fondo del vidrio, una mujer rebusca cada detalle de mis defectos, sube su mirada por mi espalda y se resigna a que no se puede hacer 
mucho por hoy. Me he pintado los ojos tratando de ocultar que ya no tengo mirada.

Les juro que podría andar con los ojos cerrados por estas calles, mis pies conocen ya cada hueco en la acera y cada rumbo en las esquinas. Aquí el tiempo pasa con garras, lento, llevándose tiras de piel en cada atardecer; tal vez por eso la gente camina rápido, como si fuera perseguida por algo.

En el feo autobús de la ciudad, reviso con temor uno de tantos periódicos del día. Como siempre la sangre, el escándalo y los gritos. ¡Esos gritos! Los de las fotografías, me lastiman, son murmullo de algo tan cerca y tan lejos. Cuando por fin logro acomodar dos palabras que formen un lánguido verso, juna imagen! Una ambulancia desesperada pasa a unos metros de mí, dejándome una angustia en el pecho, sintiendo que el tiempo es cóncavo, que entre el nacer y el morir solo existe un día, una noche larga y el silencio.

Soy un papalote colorido en una pintura a blanco y negro, así, volando sin aire, atrapada en la soledad del cielo, y sin embargo de alguna manera libre... sí, como un papalote. Todo es tan triste aquí... perdón, yo soy tan triste aquí. Soy una mujer ajena bajo este sol, idealizada por algunos miopes, me defino en mí misma, soy yo la que cuenta las horas. Extrañamente siento nostalgia por lo que no conozco, un deseo inmenso de volver, un instinto de fuga irrealizable, un ardor dislocado por las mentiras, un...un..., no puedo más. Confundida entre la dicha y el dolor de ser mujer, me desvanezco como la luna.

¡Sí! A esto huele la felicidad, pienso mientras escojo cuál flor llevar a morir conmigo. Una luz me toca el rostro y es el sol que se esconde, un milagro, el crepúsculo. Allá, lejano, lento como todo lo bello, uñas de rayo se aferran al viejo cielo, creando el nuevo cielo, y entre los colores viene delirando anciana la noche. Este girasol me encanta. Sin motivo, camino de frente al ocaso, lo busco, que me lleve. Por favor. Al llegar a la esquina era ya muy tarde, el sol había muerto.
Las puertas de un tibio lugar me invitan a pasar. Un rótulo con luz tenue e incesante me muestra el nombre de mi destino: El Teatro del Marqués. Desde la entrada busco una silla alejada. Afuera sigue la ciudad corriendo, no sé si de lo que se avecina o de ella misma. Avanzo entre las mesas y se cierran detrás de mí las puertas, mostrando cada vez menos cómo todo pasa sin importar, sin ya importarme nada realmente.

Al sentarme reparo en que no tengo mi girasol, lo he perdido. Mis párpados se niegan a levantarse y entre ellos siento una fría gota, que brota y cae sin culpa de ser lágrima, como yo. La siento fluir, viene avanzando desde mi cuerpo, cristalina, redonda, húmeda. Casi como una esfera que guarda toda mi complejidad y mis emociones desordenadas, las punzadas en mi vientre, el dolor de cintura que me dobla. ¿Por qué se preguntan tanto por nosotras, si nosotras casi nunca lo hacemos por ustedes? Hace mucho tiempo que no perdía nada.

Harta de todo poema y toda mentira levanto mi copa y me bebo las desgracias del mundo. El vino toca mis labios, la marea sube $y$ baja, y por entre la tersura de mis dientes $y$ el calor suave de mi lengua viene saliendo a pedazos mi alma, los vestigios de mi risa y mi amor. Bajo la copa y busco, en el vino tinto, el mañana, mi condición de ángel o bruja. Flotando, fatalmente, miro ahora con indiferencia una pequeña mariposa celeste, que en cada agónico movimiento se disipa en el líquido, los colores se pierden, y se siente como algo el no sentir nada en absoluto.

Les pido me disculpen si les he hecho perder el tiempo, yo sé que no todo lo escrito es digno de lectura, pero es que las mariposas de panza le dan a mi vida la magia que creí perdida. La había buscado en la fantasía, en lo irreal, y siempre estuvo tan cerca de mí, en mi panza, en Valentina.

Poco me importa si la gente ya no cree en la magia de lo cotidiano, yo lo creo y ella también. Y no podría terminar esta noche sin intentar de nuevo transformar en palabras lo 
incapturable de la poesía que emana de mi esposa mientras duerme. Si lo desean pueden dejar hasta este punto la lectura, he dicho lo suficiente; de lo contrario, serán testigos de mis absurdos intentos literarios, de mi necedad, y de la prueba de que todavía existen ancianos que le escriben cartas de amor a su esposa.

\section{$\underline{\text { Carta a Valentina }}$}

Amada Valentina:

Después de tantos años la piel se nos ha puesto suave, corroída por el viento, marchita por el sol. Las cicatrices se han perdido entre las arrugas y aunque sabemos que están allí, ya no las buscamos. Todavía en las noches, cuando nos quema el frío, siento el leve calor que tu cuerpo comparte conmigo y con tu ropa. Amo abrazarte cuando toses, decirte que estamos viejos, lentos y en silencio. Después, me regalas una sonrisa y pones tu mano manchada en mi débil pecho que ahora solo sirve para respirar y de almohada para tus canas. Amo cuando salimos a andar por la ciudad, pero más cuando encontramos césped y te aferras a mi brazo como cuando atravesábamos selvas en busca de las mariposas perdidas. Amo la brisa que corre el pañuelo de tu cabeza y hace volar mi sombrero. $\mathrm{Y}$ es que así han sido las noches contigo, como el viento. Presurosas de alcanzar el descanso, de amanecer juntos, de comenzar a vivir a nuestra edad. Yo ya no sé llorar, lo he olvidado, tal vez por eso te escribo con todo. No me gusta buscarte en los recuerdos, te encuentro aquí durmiendo frente a mí, deseando no despertar, porque los dos sabemos que ya la muerte no nos asusta, es nuestra promesa.

¿Te acuerdas de las Mariposas de Panza? De cómo fui testigo de aquella lágrima, de cómo imaginábamos la mariposa de cristal, el significado de los colores. Me hiciste prometer que algún día seríamos hogar de miles y miles de mariposas. Con cada una que sentíamos, inventábamos una historia, nos reíamos de nosotros, de nuestra locura, de cuando nos enojábamos si alguien no nos creía que todos tenemos mariposas de panza. Me has llenado el pecho de felicidad, has mantenido mis ojos con brillo desde siempre y cuando muera no quedará luz, pero sí la sonrisa, como esa después de toser. Amo hacerte tomar tus medicinas, y más aun cuando te niegas y sigues arreglando las flores que cada semana pones en mi escritorio. Serán eternos y secretos los bailes en la sala, adornados de imaginación, en nuestro castillo lleno de luces, con nuestra bohemia anciana, con nuestros versos ajenos, para solo mirarnos sin buscar más de lo que ya somos: dos niños envejecidos.

Es una noche hermosa allá afuera y aquí adentro. Ya no viajo solo por las ciudades, ya encuentro a todas las mujeres en ti, ya la prisa de la vida nos espera en el sillón, y tú..., y tú duermes entre sobresaltos, soñando que corres por la playa, dejando en las personas mariposas a tu paso. Sueñas a veces en acuarela y yo en blanco y negro, que todavía trabajo en la costa con las tortugas, joven, presintiéndote en un violento ocaso, extrañándote sin conocerte.

$\mathrm{Y}$ es que me he ganado tu corazón, $\mathrm{y}$ lo grito como el mayor triunfo de cualquier persona. Vienen los versos desde tu respiración y yo no encuentro cómo transformarlos en palabras. Tiempo atrás deseé capturarte como a la noche, tu frío, tu danza por mi vida, tu forma de acariciarme a la distancia, tus labios que no conocen el tiempo, tu silencio que nos consuela, tus años tan míos, los míos tan tuyos; pero eres la noche: inmensa, incapturable, distante. Amo esta muerte poética de la vida, donde en nuestra cama, que fue nuestra primera nube, hemos logrado sobrevivir a tantas tristezas, y tú, a mi tristeza.

Te miro dormir y estás en paz, reposando en mi vigilia, añorando partes del pasado, suspirando en el presente y entregando al futuro lo más real que tienes en tus manos: mi amor torpe y mis palabras mal construidas.

Miro mi mano que escribe, temblorosa y manchada, y si todavía lo hago es porque me encanta sacarte lágrimas de ternura. Y si alguien me lee, diré que es tu obra, porque yo sin tu 
presencia solo soy un viejo que espera la muerte y se niega a escribir. Después de tantos años, la piel se nos ha puesto suave.

Aquellos soñadores que, a pesar de tantas heridas y caídas, han logrado peregrinar por la vida sin dejar de ser felices y sin saber lo que es sentirse realmente vacios, aquellos que han llegado a conocer los años que parecían tan distantes, llegan a ser hogar de miles y miles de mariposas. Estos irradian magia por sí solos. Al morir, con el último suspiro, salen volando hacia el cielo todas las mariposas y solo queda una, la favorita, llena de luz. Esta, aún con vida, sube revoloteando por el cuerpo ya inerte de su dueño, llevando consigo el ruido, dejando solo el silencio. Y por la garganta sube, buscando la boca, donde finalmente se postra con sus alas bien abiertas, dejándose apagar suavemente, para así juntos caminar por la momentánea oscuridad. Y para los vivos que no comprenden la muerte, y solo miran tristes el cuerpo, queda una pista: el único rastro de tan increíble historia de mariposas, la sonrisa. La sonrisa de un muerto que vuelve acompañado a casa. 